\title{
Prevalence and etiologies of pulmonary hypertension in Africa: a systematic review and meta-analysis
}

Jean Joel Bigna ${ }^{1,2^{*}}$, Jean Jacques Noubiap ${ }^{3}$, Jobert Richie Nansseu ${ }^{4,5,6}$ and Leopold Ndemnge Aminde ${ }^{7,8}$

\begin{abstract}
Background: Despite the recent increasing worldwide attention towards pulmonary hypertension (PH), its epidemiology remains poorly described in Africa. Accordingly, we performed a systematic review and meta-analysis of PH prevalence, incidence and etiologies in Africa.

Methods: We searched PubMed, EMBASE, African Journals Online, and Africa Index Medicus. Published observational studies until September 20, 2017, including adult participants residing in Africa were considered. Two review authors independently selected studies, assessed included studies for methodological quality, and extracted data. A randomeffects model was used for meta-analysis. Heterogeneity was evaluated by the $x^{2}$ test on Cochrane's $Q$ statistic which is quantified by $I^{2}$ values. Using Newcastle-Ottawa Scale, we considered a score of $0-4,5-7$, and 8-10 as indicative of high, moderate, and low risk of bias in included studies, respectively.

Results: Of 1611 entries, 25 studies were retained. Twelve (48\%), seven (28\%), and six (24\%) papers had respectively a low, moderate and high risk of bias. The prevalence of PH widely varied across different populations: $9.8 \%$ (95\% confidence interval: $3.2-19.3 ; I^{2}=99.4 \% ; 6$ studies) in 11,163 people presenting with cardiac complaints; $10.6 \%\left(4.3-19.1 ; I^{2}=90.3 \% ; 4\right.$ studies) in 937 HIV-infected people; $32.9 \%\left(17.6-50.4 ;\left.\right|^{2}=97.2 \% ; 3\right.$ studies $)$ in 2077 patients with heart failure; $23.2 \%\left(15.2-32.2 ; 1^{2}=59.4 \% ; 3\right.$ studies $)$ in 248 patients on hemodialysis; $12.9 \%$ $\left(11.8-14.0 ; I^{2}=79.7 \% ; 2\right.$ studies) in 3750 patients with rheumatic heart disease; $36.9 \%\left(29.7-44.3 ; I^{2}=79.7\right.$; 2 studies) in 79 patients with sickle cell disease; $62.7 \%$ (49.0-74.7; 1 study) in 51 patients with chronic obstructive pulmonary disease; 25.4\% (16.3-37.3; 1 study) in 63 patients with systemic lupus erythematous; 68.7\% (62.8-74.1; 1 study) in 259 patients with cardiac surgery; and 7.4\% (4.6-11.9; 1 study) in 202 patients with systemic sclerosis. No study reported PH incidence. From one international study $(n=209)$, PH etiologies were: left heart disease (68.9\%), pulmonary arterial hypertension (15.8\%), lung disease and/or hypoxia (12.0\%), chronic thromboembolic PH (1.9\%) and unclear/multifactorial PH (15.8\%).
\end{abstract}

Conclusion: The prevalence of PH is relatively high in some populations in Africa, perhaps mainly driven by left heart diseases, highlighting the need for context-specific interventions.

Keywords: Pulmonary hypertension, Pulmonary arterial hypertension, Africa, Systematic review, Meta-analysis, Epidemiology

\footnotetext{
* Correspondence: bignarimjj@yahoo.fr

${ }^{1}$ Department of Epidemiology and Public Health, Centre Pasteur of Cameroon, Yaoundé, Cameroon

${ }^{2}$ Faculty of Medicine, University of Paris Sud XI, Le Kremlin Bicêtre, France

Full list of author information is available at the end of the article
} 


\section{Background}

Pulmonary hypertension (PH) is a hemodynamic and pathophysiological condition characterized by abnormally elevated pressures in the pulmonary vasculature. It is defined by a mean pulmonary arterial pressure $\geq 25 \mathrm{mmHg}$ at rest by right heart catheterization [1]. PH can be caused by an increase in pulmonary blood flow, pulmonary vascular resistance, pulmonary venous pressure or a combination of these factors. It is classified into five main groups of causes, each group sharing similar pathophysiological features: pulmonary arterial hypertension (group 1), $\mathrm{PH}$ due to left heart disease (group 2), PH due to lung disease and/or hypoxia (group 3), chronic thromboembolic $\mathrm{PH}$ (group 4) and $\mathrm{PH}$ with unclear/multifactorial mechanisms (group 5) [2].

Irrespective of the cause, $\mathrm{PH}$ is associated with debilitating symptoms and reduced life expectancy. Late diagnosis and ineffective treatment are the main drivers of its poor survival $[3,4]$. For instance, pulmonary arterial hypertension (PAH) has a median survival of 2.8 years if the patient is not treated with improved treatment regimens [5]. Following the introduction of PAH improved treatment regimens, the prognosis of $\mathrm{PAH}$ has improved considerably, with 1-, 3-, and 5-year survival rates of $85 \%, 68 \%$, and $57 \%$, respectively [6]. Early diagnosis and appropriate treatment of $\mathrm{PH}$ are therefore paramount in order to improve its outcomes. Many known risk factors for $\mathrm{PH}$ are hyperendemic in Africa, including human immunodeficiency virus (HIV) infection, acquired immunodeficiency syndrome (AIDS), rheumatic heart disease, chronic hepatitis $\mathrm{B}$ and $\mathrm{C}$, hereditary hemoglobinopathies, tuberculosis, asthma, and schistosomiasis [7-16]. Moreover, left heart disease which is increasingly prevalent in African populations has been shown to be an important cause of $\mathrm{PH}$ across the continent $[14,15$, 17]. Therefore, the epidemiological and clinical profiles of diseases differ from country to country and from continent to continent. It is why precise knowledge of region-specific epidemiology of $\mathrm{PH}$ is crucial to implement effective preventive strategies and for contextualized clinical guidelines.

Despite the point made above and the potential risk of highly prevalent $\mathrm{PH}$, the epidemiology of $\mathrm{PH}$ remains poorly described in Africa. In fact, there is a lack of studies on PH prevalence from this continent [16]. High prevalence of $\mathrm{PH}$ risk factors, specific genetic background and lifestyles, poor access to health care suggest that the epidemiology of PH in Africa may be unique.

Herein, we present the first systematic review and meta-analysis which synthesizes the current knowledge on the epidemiology of $\mathrm{PH}$ in Africa. Our objective was to determine the prevalence, the incidence and the etiologies of $\mathrm{PH}$ among people residing in Africa. The ultimate goal of this review is to provide evidence which could guide contextualized policies for the prevention and treatment of $\mathrm{PH}$ in Africa, and underpin further research.

\section{Methods}

The MOOSE guidelines served as the template for reporting the present review [18]. This review was registered in the PROSPERO International Prospective Register of systematic reviews, registration number CRD42016049351 and its protocol was published [19].

\section{Criteria for considering studies for the review}

Published observational studies until September 20, 2017, including adult (18 years or older) participants residing in Africa were considered. Studies were also considered if the diagnosis of $\mathrm{PH}$ was based on right heart catheterization with a mean pulmonary arterial hypertension $\geq 25 \mathrm{mmHg}$ or Doppler echocardiography examination with pulmonary arterial systolic pressure $>35 \mathrm{mmHg}$ [1].

\section{Search strategy for identifying relevant studies}

An expert librarian performed a search of PubMed/ MEDLINE, Excerpta Medica Database, African Journals Online and African Index Medicus without any language restriction. The search strategy included the following terms: 'Africa,' 'pulmonary hypertension', and 'pulmonary arterial hypertension'. Individual country names for the 54 African countries were also used as additional key search terms to identify more abstracts on the subject. References of all relevant original and review articles were scrutinized for additional potential data sources. The main search strategy conducted in PubMed is available in the review protocol [19].

\section{Study selection}

Two review authors (JJB and JJN) independently screened abstracts and then full texts. They consensually retained all studies to be included in the review, and disagreements were solved by arbitration of a third review author (JRN).

\section{Assessment of the methodological quality of included studies}

The Newcastle-Ottawa Scale was used to evaluate the methodological quality of studies included in this review [20]. There is no validation study that provides a cut-off score for rating low-quality studies. We considered 0-4, $5-7$, and 8-10 stars as indicative of high, moderate, and low risk of bias, respectively. Two investigators (JJB and JJN) independently assessed study quality, with disagreements resolved by consensus. 


\section{Data extraction and management}

Two review authors (JJB and JJN) independently extracted data including: first author name, year of publication, year of participants' inclusion, country, study design, setting, sample size, age distribution, proportion of males, diagnostic criteria for $\mathrm{PH}$, number of cases of $\mathrm{PH}$, and etiologies of $\mathrm{PH}$ as classified by international guidelines [2]. Authors were contacted at least twice to request relevant missing information. A World Health Organization Afro sub-region was assigned to each study based on the country of recruitment.

\section{Data synthesis and analysis}

A meta-analysis was conducted for data obtained from studies in the same population (patients with chronic obstructive pulmonary disease, with heart failure, on hemodialysis, presenting with cardiac complaints, with HIV infection, with rheumatic heart disease, with sickle cell disease, with systemic lupus erythematous, with cardiac surgery, and with systemic sclerosis). Standard errors for the study-specific estimates were determined from the point estimate and the appropriate denominators. Then, the study-specific estimates were pooled through a random-effects meta-analysis model, to obtain an overall summary estimate of the prevalence across studies, after stabilizing the variance of individual studies using the Freeman-Tukey double arc-sine transformation [21]. Heterogeneity was evaluated by the $\chi 2$ test on Cochrane's $\mathrm{Q}$ statistic which is quantified by $\mathrm{I}^{2}$ values [22], assuming that $\mathrm{I}^{2}$ values of $25 \%, 50 \%$ and $75 \%$ respectively represent low, medium and high heterogeneity [23]. Inter-rater agreement for study inclusion was assessed using Cohen's kappa ( $\mathrm{k}$ ) coefficient [24]. Egger's test served to detect publication bias [25]. A $p$ value $<0.1$ was considered indicative of statistically significant publication bias. Data were analyzed using Stata software (Stata Corp. 2013. Stata Statistical Software: Release 13. College Station, TX: StataCorp LP). We conducted a narrative synthesis in the case of limited data for a meta-analysis.

\section{Results}

\section{The review process}

Initially, a total of 1611 records were identified. After elimination of duplicates, 1543 records were retained. Titles and abstracts were screened and 1470 records were found irrelevant and excluded. Agreement between review authors on abstract selection was moderate $(\kappa=0.69)$. Full-texts of the remaining 73 papers were scrutinized for eligibility, among which 48 were excluded (Fig. 1). Overall, 25 papers were found eligible and were included in the data synthesis; 24 papers reported the prevalence of $\mathrm{PH}$ [26-49], while one other paper reported PH etiologies [17]. The inter-rater agreement for final study inclusion between review authors was high $(\kappa=0.93)$.

\section{Methodological quality and characteristics of included studies}

The characteristics of each included study are presented in Additional file 1. Twelve (48\%), seven (28\%), and six (24\%) papers had respectively a low, moderate and high risk of bias in their methodological quality [See Additional file 2]; all were cross sectional studies. The diagnosis of $\mathrm{PH}$ was performed using right heart catheterization in only one study while the rest used echocardiography. The studies included were published from 2003 to 2017 and reported surveys conducted from 2004 to 2015. Eight studies were from Northern, five from Central, four from Eastern, three from Southern,

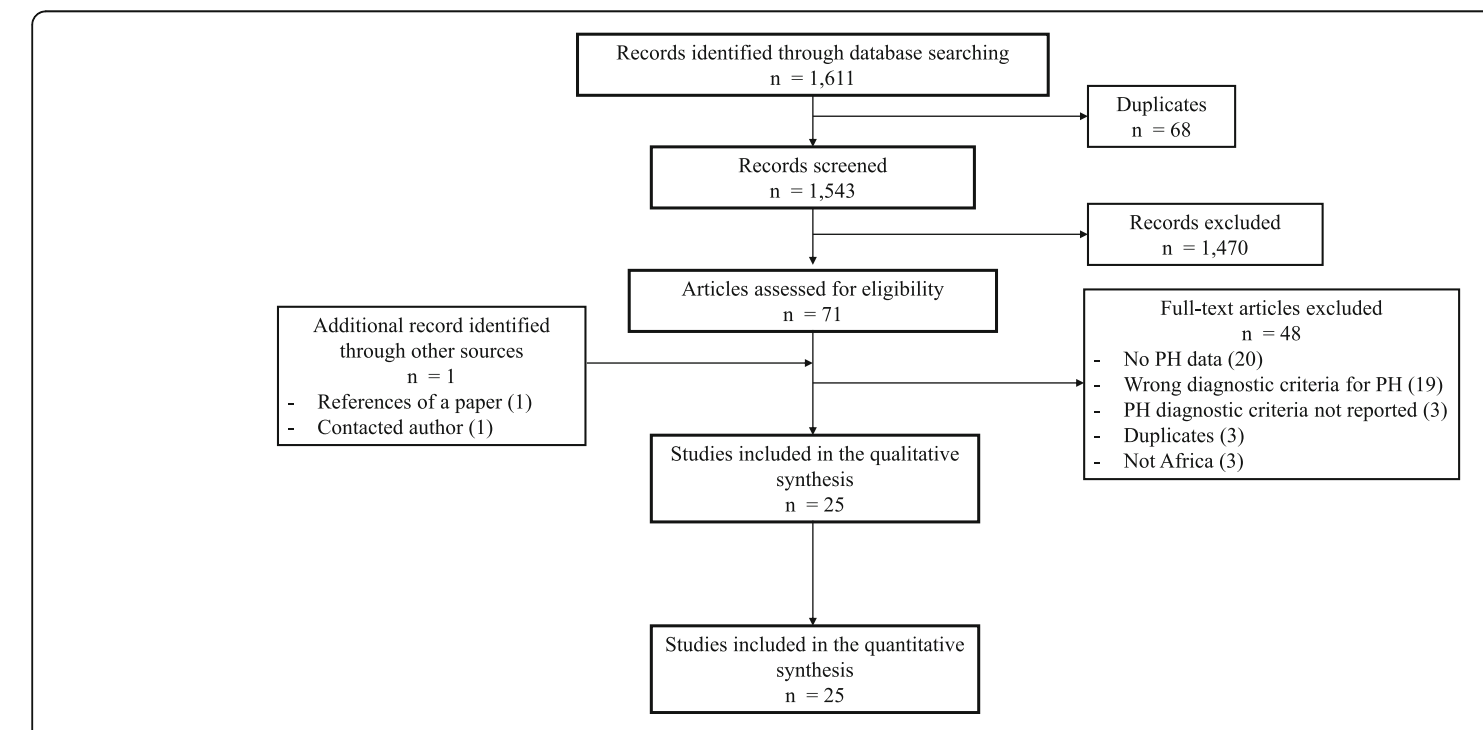

Fig. 1 The review process 
and three from Western Africa. Two studies included data from different countries. Nineteen studies prospectively collected data and the others, retrospectively. Twenty-four studies included participants from both rural and urban areas and one from urban areas only. Participants were randomly selected only in two studies. Twenty-three studies were hospital-based and the others were community-based. Mean/median ages reported in 18 studies varied from 27 to 64 years; the age ranged from 17 to 98 years. The male proportion reported in 17 studies varied from 5 to $100 \%$.

\section{Prevalence and incidence of pulmonary hypertension in Africa}

Figure 2 presents the prevalence of $\mathrm{PH}$ in specific groups. Among patients presenting with cardiac complaints, the prevalence was $9.8 \%, 95 \%$ confidence interval (CI): $3.2-19.3, \mathrm{I}^{2}=99.4 \%$; in 11,163 participants from six studies conducted in Cameroon, Congo Brazzaville, Ethiopia, Libya and South Africa ( $\mathrm{p}$ Egger $=0.478$ ) [26, 33, 37, 45, 46, 49]. Among HIV-infected patients presenting with cardiac complaints, the prevalence was $10.6 \%$ (95\%CI: $\left.4.3-19.1 ; \mathrm{I}^{2}=99.6 \%\right)$ in a pooled sample of 937 patients from four studies conducted in different countries including Cameroon, Mozambique, South Africa and Tanzania (p Egger $=0.351)[28,38,40,43]$. A prevalence of $32.9 \%$ (95\%CI: $17.6-50.4 ; \mathrm{I}^{2}=97.2 \%$ ) was found in a pooled sample of 2077 patients with heart failure from three studies conducted in Morocco and Nigeria $(\mathrm{p}$ Egger $=0.445) \quad[30,31,35]$. A prevalence of $23.2 \%\left(95 \%\right.$ CI: $\left.15.2-32.2 ; \mathrm{I}^{2}=59.4 \%\right)$ was found in a pooled sample of 248 patients undergoing hemodialysis from three studies conducted in Egypt and Morocco (p Egger $=0.376)$ [27, 32, 47]. A prevalence of $12.9 \%\left(95 \% \mathrm{CI}: \quad 11.8-14.0 ; \mathrm{I}^{2}=96.8 \%\right)$ was found in a pooled sample of 3750 patients with

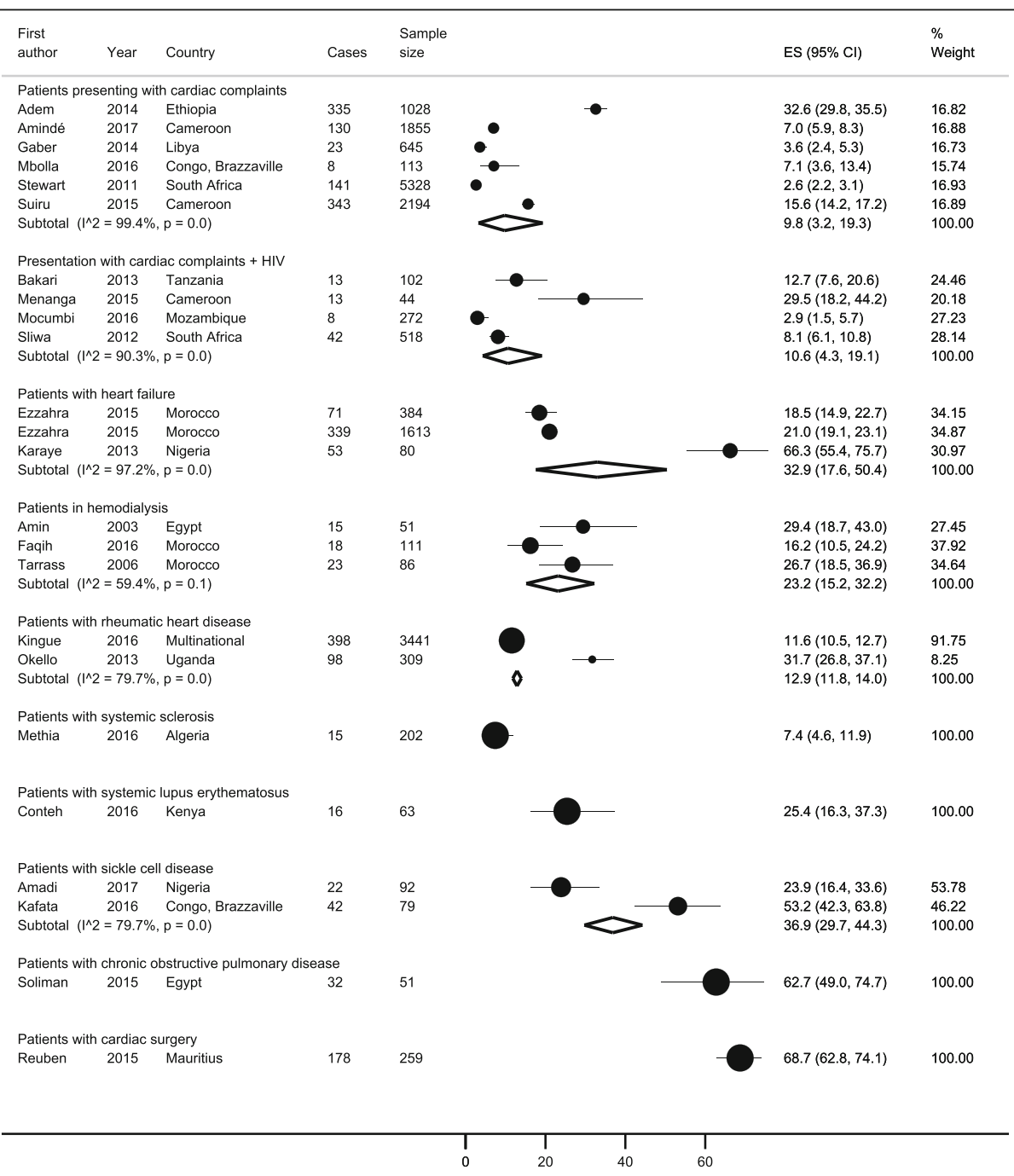

Fig. 2 Meta-analysis results for prevalence of pulmonary hypertension in Africa 
rheumatic heart disease from two studies, one from Uganda and one international (Cameroon, Ivory Coast, Guinea-Conakry, Mali, Nigeria, Senegal, and Togo) [36, 41]. A prevalence of $36.9 \%$ (95\%CI $29.7-44.3 ; \mathrm{I}^{2}=79.7$ ) was found in a pooled sample of 171 people with sickle cell disease from two studies conducted in Congo Brazzaville and Nigeria [34, 48].

In one study conducted in Egypt, the prevalence of $\mathrm{PH}$ was $62.7 \%$ (95\%CI: 49.0-74.7) among 51 patients with chronic obstructive pulmonary disease [44]. One other study reported a prevalence of $25.4 \%$ (95\%CI: 16.3-37.3) in 63 patients with systemic lupus erythematous in Kenya [29]. In one study conducted in Mauritius, the prevalence of $\mathrm{PH}$ was $68.7 \%$ (95\%CI: 62.8-74.1) among 259 patients with cardiac surgery [42]. One study reported a prevalence of $7.4 \%$ (95\%CI: 4.6-11.9) in 202 patients with systemic sclerosis in Algeria [39]. No study reported the incidence of $\mathrm{PH}$.

\section{Etiologies of pulmonary hypertension in Africa}

Only one study, the Pan African Pulmonary hypertension Cohort (PAPUCO) study, reported the etiologies of $\mathrm{PH}$ as classified by Simmoneau and colleagues [17]. This study included 209 subjects with a median age of 48 years; the study population comprised $41 \%$ of males and $35 \%$ of HIV-infected patients recruited in Cardiology units in Cameroon, Mozambique, Nigeria and South Africa. The etiologies were distributed as follows: $144(68.9 \%)$ presented with PH due to left heart disease, 33 (15.8\%) with $\mathrm{PAH}, 25$ (12.0\%) with $\mathrm{PH}$ due to lung disease and/or hypoxia, $4(1.9 \%)$ with chronic thromboembolic $\mathrm{PH}$ and 33 (15.8\%) with unclear/multifactorial PH.

\section{Discussion}

Although, we have neither found studies reporting the prevalence of $\mathrm{PH}$ in the general population nor those reporting the incidence of $\mathrm{PH}$ in Africa, available studies showed that the prevalence of $\mathrm{PH}$ may vary widely across specific populations: from $7.4 \%$ in patients with systemic sclerosis to $68.7 \%$ in patients with cardiac surgery. The main driver of $\mathrm{PH}$ among patients presenting with cardiac complaints may be left-sided heart disease, which seems to represent two-thirds of $\mathrm{PH}$ etiologies in Africa.

Among patients presenting with cardiac complaints, the prevalence of $\mathrm{PH}$ was $9.8 \%$ which is in the $10-20 \%$ range reported in the US general population [50]. In more specific populations, we found a high prevalence of $\mathrm{PH}$ in patients with well-known causes of $\mathrm{PH}$ including group 1: systemic lupus erythematous (25.4\%), systemic sclerosis (7.4\%), and HIV infection (10.6\%). The prevalence of $\mathrm{PH}$ in patients with systemic sclerosis in this review was close to the prevalence reported in developed countries, albeit measured with right heart catheterization [51]. Concerning HIV-infected people, our prevalence estimate is almost on par with a previous review in the same population in Africa [9]. The prevalence of $\mathrm{PH}$ among HIV-infected individuals in Africa remains higher than the $0.5 \%$ reported from developed countries [52-54]. This can be explained by several reasons including low access and retention in care of HIVinfected people in Africa leading to late diagnosis and management of HIV disease (antiretroviral therapy initiation) $[9,55-58]$. Further, we noticed a higher prevalence of $\mathrm{PH}$ among Africans with systemic lupus erythematous compared to the prevalence reported in developed countries $(0.5-17.5 \%)$ [51]. Due to fact, that many known risk factors for $\mathrm{PH}$ are hyperendemic in Africa [7-16], patients with systemic lupus erythematous or HIV residing in Africa probably had other comorbid conditions favoring the occurrence of $\mathrm{PH}$.

Group 2 causes included: rheumatic heart disease $(12.9 \%)$, heart failure (32.9\%), and cardiac surgery (68.7\%). Similarly, a recent global systematic review by Dzudie and colleagues reported a prevalence of $\mathrm{PH}$ varying from 22 to $83.3 \%$ in adults with left heart disease $[17,59]$. Indeed, left heart diseases represent the most common causes of $\mathrm{PH}$ [60-62]. Actually, it has been observed that even after surgery for rheumatic heart disease complicated by $\mathrm{PH}$, some residual $\mathrm{PH}$ is seen to persist [63].

For group 3 causes of $\mathrm{PH}$, we found a single study from Egypt, which reported a prevalence of $62.7 \%$ among those with chronic obstructive pulmonary disease. This is higher than findings from developed countries among patients with end-stage chronic obstructive pulmonary disease (48.7\%) [64]. For group 5 causes of $\mathrm{PH}$, the $23.2 \%$ prevalence of $\mathrm{PH}$ in patients with hemodialysis in our review falls within the range reported from other settings (18.8-68.8\%) [65]. In contrast to developed countries where the reviews on the prevalence of $\mathrm{PH}$ in sickle cell disease individuals reported a range between 6 and 11\% [66, 67], we found that 36.9\% of patients with sickle cell disease had PH. We found no study conducted among patients with group $4 \mathrm{PH}$ (chronic thromboembolic PH). While this might look like a rarity of chronic thromboembolic $\mathrm{PH}$ in Africa, the limited availability (and affordability) of the complex diagnostic tools investigating lung function required for accurate diagnosis of this form of $\mathrm{PH}$, likely explains the dearth in studies and potentially underdiagnoses.

Overarchingly, one can note that the prevalence of $\mathrm{PH}$ in different specific populations in Africa is either similar to, or in the majority of situations higher than that reported in other non-African settings. This is potentially explained by the presence of many known endemic risk factors for $\mathrm{PH}$ in Africa (some not fully explored) [7-16]. We found just one study classifying PH according to current guidelines. Despite the dearth in studies, 
available evidence suggests that the main class of $\mathrm{PH}$ in Africa is the one due to left heart diseases which is consistent with prior literature [62, 68-70].

About half of studies included in this review had a low risk of bias in their methodological quality. We observed no publication bias, suggesting that future research endeavors are likely to have no important impact on the confidence in our estimates. A key exclusion criterion for studies during the review process was wrong diagnostic criteria for PH (i.e. a cut-off different from $35 \mathrm{mmHg}$ for pulmonary arterial systolic pressure on echocardiography). Indeed, some studies used a cut-off between 20 and $30 \mathrm{mmHg}$ [71-79] and others between 37 and $50 \mathrm{mmHg}$ [80-85] on echocardiography. Most studies in this review used Doppler echography for the diagnosis of $\mathrm{PH}$, and were hospital-based; moreover, $\mathrm{PH}$ was mainly symptom-driven (vs. general population). In this respect, interpretation of our findings should be done with caution.

Further studies are needed to investigate $\mathrm{PH}$ etiologies in Africa. Clinicians and researchers are invited to comply with updated guidelines for accurate diagnosis and classification of $\mathrm{PH}$, as recommended by international guidelines [86]. While the PAPUCO study [17] was a commendable effort describing the natural history of $\mathrm{PH}$ in Africa, there is still need for further studies and collaborations to expand these strides and provide more robust evidence for Africa. However, the high prevalence of $\mathrm{PH}$ found in this review, albeit in specific populations, underscores the need for clinicians, policy makers, researchers and stakeholders to direct more attention towards $\mathrm{PH}$ in a bid to improve detection and management of the disease throughout the continent. What we need in Africa are studies that can develop some clinical screening methods that can help to identify almost all $\mathrm{PH}$ cases in community. Indeed, early diagnosis and timely access to care can improve the clinical course of the disease and potentially reduce its burden. The greatest difficulty is to know how to ensure that everyone at risk to develop PH has access to its eventual diagnosis in a weak healthcare system and in a context of constrained resources. We also hope that all these efforts will bring to define local and adapted guidelines for the diagnosis and management of $\mathrm{PH}$ in Africa, taking into account the specific patterns of the disease across the continent.

This review had some limitations. First, although we searched several databases, this review is based on a limited number of original studies published in specific populations. Second, the limited number of studies included in the review did not permit us to perform meaningful subgroup analyses to determine sources of heterogeneity. Third, not all African sub-regions were represented in all the specific populations, making the results of this study particular in terms of generalizability to the entire continent. Nonetheless, this is the first comprehensive review on the prevalence, incidence and etiologies of $\mathrm{PH}$ in Africa; it gives a clear overview of the burden of $\mathrm{PH}$ in Africa and crucial gaps to fill in future research.

\section{Conclusions}

This review suggests that the prevalence of $\mathrm{PH}$ is relatively high in some populations in the African context. These high prevalence estimates seem to be driven by left heart diseases. To tackle this high disease burden, policy makers and healthcare providers must be aware of this reality and invest in interventions towards improving prevention, detection and management of $\mathrm{PH}$ in Africa. Community-based studies are required to better characterize the epidemiology and natural history of $\mathrm{PH}$ in Africa.

\section{Additional files}

Additional file 1: Individual characteristics of included studies. (PDF $634 \mathrm{~kb}$ ) Additional file 2: Risk of bias in individual studies. (PDF 287 kb)

\section{Abbreviations}

PAH: Pulmonary arterial hypertension; PAPUCO: Pan African Pulmonary hypertension Cohort study; PH: Pulmonary hypertension

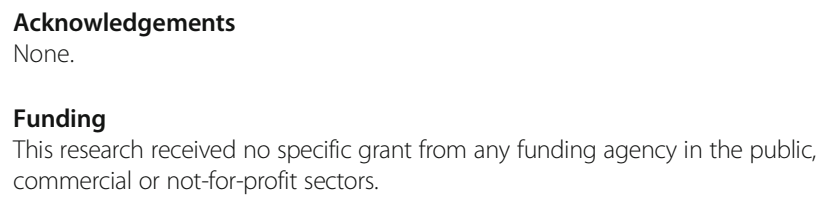

Authors' contributions

$J J B$ and JJN conceived the study and, together with JRN and LNA, designed the protocol. JJB and LNA involved in the literature search. JJB and JJN selected the studies and extracted the relevant information. JJB synthesized and interpreted data. JJB and JJN wrote the first draft of the paper. JJB, JJN, JRN and LNA critically revised successive drafts of the paper and approved its final version.

Ethics approval and consent to participate

Not applicable.

\section{Consent for publication}

Not applicable.

Competing interests

The authors declare that they have no competing interests.

\section{Publisher's Note}

Springer Nature remains neutral with regard to jurisdictional claims in published maps and institutional affiliations.

\section{Author details}

${ }^{1}$ Department of Epidemiology and Public Health, Centre Pasteur of Cameroon, Yaoundé, Cameroon. 'Faculty of Medicine, University of Paris Sud $\mathrm{XI}$, Le Kremlin Bicêtre, France. ${ }^{3}$ Department of Medicine, Groote Schuur Hospital and University of Cape Town, Cape Town, South Africa. 
${ }^{4}$ Department of Public Health, Faculty of Medicine and Biomedical Sciences, University of Yaoundé 1, Yaoundé, Cameroon. ${ }^{5}$ Sickle Cell Disease Unit, Mother and Child Centre of the Chantal Biya Foundation, Yaoundé, Cameroon. ${ }^{6}$ Department of Disease, Epidemics and Pandemics Control, Ministry of Public Health, Yaoundé, Cameroon. ${ }^{7}$ Clinical Research Education, Networking and Consultancy (CRENC), Douala, Cameroon. ${ }^{8}$ School of Public Health, Faculty of Medicine \& Biomedical Sciences, University of Queensland, Brisbane, Australia.

Received: 1 June 2017 Accepted: 30 November 2017 Published online: 08 December 2017

\section{References}

1. Hoeper MM, Bogaard HJ, Condliffe R, Frantz R, Khanna D, Kurzyna M, Langleben D, Manes A, Satoh T, Torres F, et al. Definitions and diagnosis of pulmonary hypertension. J Am Coll Cardiol. 2013;62(25 Suppl):D42-50.

2. Galie N, Humbert M, Vachiery JL, Gibbs S, Lang I, Torbicki A, Simonneau G, Peacock A, Vonk Noordegraaf A, Beghetti M, et al. 2015 ESC/ERS guidelines for the diagnosis and treatment of pulmonary hypertension: the joint task force for the diagnosis and treatment of pulmonary hypertension of the European Society of Cardiology (ESC) and the European Respiratory Society (ERS): endorsed by: Association for European Paediatric and Congenital Cardiology (AEPC), International Society for Heart and Lung Transplantation (ISHLT). Eur Respir J. 2015;46(4):903-75.

3. Tueller C, Stricker H, Soccal P, Tamm M, Aubert JD, Maggiorini M, Zwahlen M, Nicod L. Epidemiology of pulmonary hypertension: new data from the Swiss registry. Swiss Med Wkly. 2008;138(25-26):379-84.

4. Brown LM, Chen H, Halpern S, Taichman D, McGoon MD, Farber HW, Frost $A E$, Liou TG, Turner M, Feldkircher $K$, et al. Delay in recognition of pulmonary arterial hypertension: factors identified from the REVEAL registry. Chest. 2011;140(1):19-26.

5. D'Alonzo GE, Barst RJ, Ayres SM, Bergofsky EH, Brundage BH, Detre KM, Fishman AP, Goldring RM, Groves BM, Kernis JT, et al. Survival in patients with primary pulmonary hypertension. Results from a national prospective registry. Ann Intern Med. 1991;115(5):343-9.

6. Benza RL, Miller DP, Barst RJ, Badesch DB, Frost AE, McGoon MD. An evaluation of long-term survival from time of diagnosis in pulmonary arterial hypertension from the REVEAL registry. Chest. 2012;142(2):448-56.

7. Thienemann F, Sliwa K, Rockstroh JK. HIV and the heart: the impact of antiretroviral therapy: a global perspective. Eur Heart J. 2013;34(46):3538-46.

8. Mocumbi AO, Lameira E, Yaksh A, Paul L, Ferreira MB, Sidi D. Challenges on the management of congenital heart disease in developing countries. Int J Cardiol. 2011;148(3):285-8.

9. Bigna JJ, Nansseu JR, Um LN, Noumegni SR, Sime PS, Aminde LN, KoullaShiro S, Noubiap JJ. Prevalence and incidence of pulmonary hypertension among HIV-infected people in Africa: a systematic review and meta-analysis. BMJ Open. 2016;6(8):e011921.

10. Bigna JJ, Sime PS, Koulla-Shiro S. HIV related pulmonary arterial hypertension: epidemiology in Africa, physiopathology, and role of antiretroviral treatment. AIDS Res Ther. 2015;12:36.

11. World Health Organization: Shistosomiasis country maps [http://www.who. int/schistosomiasis/epidemiology/global_atlas_maps/en/]

12. Schweitzer A, Horn J, Mikolajczyk RT, Krause G, Ott JJ: Estimations of worldwide prevalence of chronic hepatitis B virus infection: a systematic review of data published between 1965 and 2013. Lancet. 2015;386(10003): 1546-55.

13. Mohd Hanafiah K, Groeger J, Flaxman AD, Wiersma ST. Global epidemiology of hepatitis C virus infection: new estimates of age-specific antibody to HCV seroprevalence. Hepatology. 2013;57(4):1333-42.

14. Sliwa K, Wilkinson D, Hansen C, Ntyintyane L, Tibazarwa K, Becker A, Stewart S. Spectrum of heart disease and risk factors in a black urban population in South Africa (the heart of Soweto study): a cohort study. Lancet. 2008; 371(9616):915-22.

15. Stewart S, Wilkinson D, Hansen C, Vaghela V, Mvungi R, McMurray J, Sliwa K. Predominance of heart failure in the heart of Soweto study cohort: emerging challenges for urban African communities. Circulation. 2008; 118(23):2360-7.

16. Thienemann F, Dzudie A, Mocumbi AO, Blauwet L, Sani MU, Karaye KM, Ogah OS, Mbanze I, Mbakwem A, Udo P, et al. Rationale and design of the pan African pulmonary hypertension cohort (PAPUCO) study: implementing a contemporary registry on pulmonary hypertension in Africa. BMJ Open. 2014;4(10):e005950.

17. Thienemann F, Dzudie A, Mocumbi AO, Blauwet L, Sani MU, Karaye KM, Ogah OS, Mbanze I, Mbakwem A, Udo P, et al. The causes, treatment, and outcome of pulmonary hypertension in Africa: insights from the pan African pulmonary hypertension cohort (PAPUCO) registry. Int J Cardiol. 2016;221:205-11.

18. Stroup DF, Berlin JA, Morton SC, Olkin I, Williamson GD, Rennie D, Moher D, Becker BJ, Sipe TA, Thacker SB. Meta-analysis of observational studies in epidemiology: a proposal for reporting. Meta-analysis of observational studies in epidemiology (MOOSE) group. JAMA. 2000;283(15):2008-12.

19. Bigna JJ, Noubiap JJ, Nansseu JR, Aminde LN. Prevalence, incidence and aetiologies of pulmonary hypertension in Africa: a systematic review and meta-analysis protocol. BMJ Open. 2017;7(6):e014768.

20. Wells GA, Shea B, O'Connell D, Peterson J, Welch V, Losos M, Tugwell P. The Newcastle-Ottawa Scale (NOS) for assessing the quality of nonrandomised studies in meta-analyses. http://www.ohri.ca/programs/clinical_ epidemiology/oxford.asp.

21. Barendregt JJ, Doi SA, Lee YY, Norman RE, Vos T. Meta-analysis of prevalence. J Epidemiol Community Health. 2013;67(11):974-8.

22. Cochran GW. The combination of estimates from different experiments. Biometrics. 1954;10(1):101-29.

23. Higgins JP, Thompson SG. Quantifying heterogeneity in a meta-analysis. Stat Med. 2002;21(11):1539-58.

24. Viera AJ, Garrett JM. Understanding interobserver agreement: the kappa statistic. Fam Med. 2005;37(5):360-3.

25. Egger M, Davey Smith G, Schneider M, Minder C. Bias in meta-analysis detected by a simple, graphical test. BMJ. 1997;315(7109):629-34.

26. Adem A, Abebe S, Hailu A, Feleke B, Berhe M, Atsibeha M, Davilla VG. Heart diseases in north ethiopia pattern of echocardiographic abnormalities among adult cardiac patients - an experience from Ayder Hospital of Mekelle University. Ethiop Med J. 2014;52(4):173-83.

27. Amin M, Fawzy A, Hamid MA, Elhendy A. Pulmonary hypertension in patients with chronic renal failure: role of parathyroid hormone and pulmonary artery calcifications. Chest. 2003;124(6):2093-7.

28. Bakari M, Chillo P, Lwakatare J: Factors associated with, and echocardiographic findings of heart failure among HIV infected patients at a tertiary health care facility in Dar es Salaam, Tanzania. Tanzan J Health Res. 2013;15(2):1-9.

29. Conteh S, Ogola EA, Oyoo GO, Gitura BM, Achieng L. Echocardiographic abnormalities in systemic lupus erythematosus patients at Kenyatta National Hospital. Afr J Rheumatol. 2016;4(1):9-13.

30. Ezzahra SF, Meriam A, Rachida H. Value of non-invasive assessment of pulmonary hypertension in heart failure with preserved ejection fraction, and its prognostic importance. Cardiovasc J Afr. 2015;26(5):29-30.

31. Ezzahra SF, Meriam A, Rachida H. Prevalence and outcomes of pulmonary hypertension and diastolic dysfunction in a heart failure population. Cardiovasc J Afr. 2015;26(5):30.

32. Faqih SA, Noto-Kadou-Kaza B, Abouamrane LM, Mtiou N, El Khayat S, Zamd M, Medkouri G, Benghanem MG, Ramdani B. Pulmonary hypertension: prevalence and risk factors. IJC Heart Vasculature. 2016;11:87-9.

33. Gaber K, Elfaitouri O, Hassi S, Embaig O, Najem S: Prevalence of pulmonary hypertension in patients attending echocardiolgy clinic in the eastern part of libya. Chest. 2014;145(3, Supplement):516A.

34. Kafata LIO, Ngolet L, Letomo KN, Bakekolo P, Gankama T, Kimbally-Kaky G, Makani J. Echocardiographic aspects of Congolese sickle cell disease heart. Arch Cardiovasc Dis Suppl. 2016;8(1):43.

35. Karaye KM, Saidu H, Bala MS, Yahaya IA. Prevalence, clinical characteristics and outcome of pulmonary hypertension among admitted heart failure patients. Ann Afr Med. 2013;12(4):197-204.

36. Kingué $\mathrm{S}, \mathrm{Ba}$ SA, Balde $\mathrm{D}$, Diarra MB, Anzouan-Kacou JB, Anisubia B, Damorou JM, Ndobo P, Menanga A, Kane A, et al. The VALVAFRIC study: a registry of rheumatic heart disease in western and Central Africa. Arch Cardiovasc Dis. 2016;109(5):321-9.

37. Mbolla BE, Kouala-Landa C, Mongo-Ngamami SF, Ikama MS, Bassakouahou JM, Bakekolo RP, Gombet TRA, Kimbally-Kaky SG. Clinical and echocardiographic profile of HIV-infected patients in cardiology Department at the University Hospital of Brazzaville (Congo). Arch Cardiovasc Dis Suppl. 2016;8(1):35.

38. Menanga AP, Ngomseu CK, Jingi AM, Mfangam BM, Noubiap JJ, Gweth MN, Blackett KN, Kinque S. Patterns of cardiovascular disease in a group of HIVinfected adults in Yaounde, Cameroon. Cardiovasc Diagn Ther. 2015;5(6):420-7. 
39. Methia N, Latreche S, Benkhedda S. Frequency of PAH in scleroderma Algerian patients. Arch Cardiovasc Dis Suppl. 2016;8(1):62

40. Mocumbi A, Majid N, Manafe N, Carlin A, Zimba I, Schooley R, Benson C. Anemia is a predictor of cardiac abnormalities and systolic function worsening in a African population with access to antiretroviral therapy. Glob Heart. 2016;11(2):e167.

41. Okello E, Wanzhu Z, Musoke C, Twalib A, Kakande B, Lwabi P, Wilson NB, Mondo CK, Odoi-Adome R, Freers J. Cardiovascular complications in newly diagnosed rheumatic heart disease patients at Mulago hospital, Uganda. Cardiovasc J Afr. 2013;24(3):80-5.

42. Reuben M. Characteristics and treatment outcomes of patients with and without pulmonary hypertension who underwent cardiac surgery at muhimbili cardiac unit from 2008 to 2012. Cardiovasc J Afr. 2015;26(5):25.

43. Sliwa K, Carrington MJ, Becker A, Thienemann F, Ntsekhe M, Stewart S Contribution of the human immunodeficiency virus/acquired immunodeficiency syndrome epidemic to de novo presentations of heart disease in the heart of Soweto study cohort. Eur Heart J. 2012; 33(7):866-74.

44. Soliman M, Heshmat $H$, Amen $Y$, Aboelhassan UE, Mahmod K. Detection of right sided heart changes and pulmonary hypertension in COPD patients. Egypt J Chest Dis Tuberc. 2015;64(2):335-41.

45. Stewart S, Mocumbi AO, Carrington MJ, Pretorius S, Burton R, Sliwa K. A not-so-rare form of heart failure in urban black Africans: pathways to right heart failure in the heart of Soweto study cohort. Eur J Heart Fail. 2011; 13(10):1070-7.

46. Suiru DB, Anastase D, Cabrai TT, Leopld A, Mocumbi AO, Martin A, Pascal KA, Friedrich T, Karen S. Pulmonary hypertension in a rural area: prevalence, correlates and clinical features from the Shisong cardiac Centre, Cameroon. Cardiovasc J Afr. 2015;26(5):14-5.

47. Tarrass F, Benjelloun M, Medkouri G, Hachim K, Benghanem MG, Ramdani B. Doppler echocardiograph evaluation of pulmonary hypertension in patients undergoing hemodialysis. Hemodial Int. 2006;10(4):356-9.

48. Amadi VN, Balogun MO, Akinola NO, Adebayo RA, Akintomide AO Pulmonary hypertension in Nigerian adults with sickle cell anemia. Vasc Health Risk Manag. 2017;13:153-60.

49. Aminde LN, Dzudie A, Kengne AP, Ndjebet J, Mapoh S, Kuelang X, Kamdem F, Mbatchou Ngahane BH, Doualla M-S, Ngu KB et al: Gender disparities in pulmonary hypertension at a tertiary centre in Cameroon. S Afr Med J 2017, In press.

50. Shah SJ. Pulmonary hypertension. JAMA. 2012;308(13):1366-74

51. Legendre P, Mouthon L. Pulmonary arterial hypertension associated with connective tissue diseases. Presse Med. 2014;43(9):957-69.

52. Sitbon O, Lascoux-Combe C, Delfraissy JF, Yeni PG, Raffi F, De Zuttere D, Gressin V, Clerson P, Sereni D, Simonneau G. Prevalence of HIV-related pulmonary arterial hypertension in the current antiretroviral therapy era. Am J Respir Crit Care Med. 2008;177(1):108-13.

53. Quezada M, Martin-Carbonero L, Soriano V, Vispo E, Valencia E, Moreno V, de Isla LP, Lennie V, Almeria C, Zamorano JL. Prevalence and risk factors associated with pulmonary hypertension in HIV-infected patients on regular follow-up. AIDS. 2012;26(11):1387-92.

54. Speich R, Jenni R, Opravil M, Pfab M, Russi EW. Primary pulmonary hypertension in HIV infection. Chest. 1991;100(5):1268-71.

55. Bigna JJ, Plottel CS, Koulla-Shiro S. Challenges in initiating antiretrovira therapy for all HIV-infected people regardless of CD4 cell count. Infect Dis Poverty. 2016:5:85

56. Kassaye SG, Katzenstein D. HIV/AIDS care and treatment in sub-Saharan Africa. AIDS Rev. 2003;5(4):195-204.

57. Giuliano M, Vella S. Inequalities in health: access to treatment for HIV/AIDS Ann Ist Super Sanita. 2007;43(4):313-6.

58. Cleary S. Equity and efficiency in scaling up access to HIV-related interventions in resource-limited settings. Curr Opin HIV AIDS. 2010;5(3):210-4.

59. Dzudie A, Kengne AP, Thienemann F, Sliwa K. Predictors of hospitalisations for heart failure and mortality in patients with pulmonary hypertension associated with left heart disease: a systematic review. BMJ Open. 2014;4(7):e004843

60. Adir Y, Amir O. Pulmonary hypertension associated with left heart disease. Semin Respir Crit Care Med. 2013;34(5):665-80

61. Haddad F, Kudelko K, Mercier O, Vrtovec B, Zamanian RT, de Jesus PV. Pulmonary hypertension associated with left heart disease: characteristics, emerging concepts, and treatment strategies. Prog Cardiovasc Dis. 2011; 54(2):154-67.
62. Thenappan T, Gomberg-Maitland M. Epidemiology of pulmonary hypertension and right ventricular failure in left heart failure. Curr Heart Fail Rep. 2014;11(4):428-35.

63. Privalova EV, Cherepenin LP, Ershov VI, Baloian GM, Buravikhina TA, Ermakov Al, Ivanov AS. Course of pulmonary hypertension in patients operated for rheumatic mitral heart disease. Terapevticheskii arkhiv. 2000;72(4):58-62.

64. Andersen $\mathrm{KH}$, Iversen M, Kjaergaard J, Mortensen J, Nielsen-Kudsk JE, Bendstrup E, Videbaek R, Carlsen J. Prevalence, predictors, and survival in pulmonary hypertension related to end-stage chronic obstructive pulmonary disease. J Heart Lung Transplant. 2012;31(4):373-80.

65. Bolignano D, Rastelli S, Agarwal R, Fliser D, Massy Z, Ortiz A, Wiecek A Martinez-Castelao A, Covic A, Goldsmith D, et al. Pulmonary hypertension in CKD. Am J Kidney Dis. 2013;61(4):612-22.

66. Gordeuk VR, Castro OL, Machado RF. Pathophysiology and treatment of pulmonary hypertension in sickle cell disease. Blood. 2016;127(7):820-8.

67. Ataga Kl, Klings ES. Pulmonary hypertension in sickle cell disease: diagnosis and management. Hematology Am Soc Hematol Educ Program. 2014. 2014(1):425-31.

68. Rosenkranz S, Gibbs JS, Wachter R, De Marco T, Vonk-Noordegraaf A, Vachiery JL. Left ventricular heart failure and pulmonary hypertension. Eur Heart J. 2016:37(12):942-54.

69. Guazzi M. Pulmonary hypertension in heart failure preserved ejection fraction: prevalence, pathophysiology, and clinical perspectives. Circ Heart Fail. 2014;7(2):367-77.

70. Zangiabadi A, De Pasquale CG, Sajkov D. Pulmonary hypertension and right heart dysfunction in chronic lung disease. Biomed Res Int. 2014;2014:739674.

71. Miller AC, Gladwin MT. Pulmonary complications of sickle cell disease. Am J Respir Crit Care Med. 2012;185(11):1154-65.

72. Badawy MS, El-Senbesy MA, Mahmoud HS. Evaluation of pulmonary hypertension in Bilharzial patients. Egypt J Chest Dis Tuberc. 2013;62(2):305-9.

73. Dosunmu AO, Balogun TM, Adeyeye OO, Daniel FA, Akinola RA, Onakoya JA, Akinbami AA, Sagoe AO, Onadeko BO. Prevalence of pulmonary hypertension in sickle cell anaemia patients of a tertiary hospital in Nigeria. Niger Med J. 2014;55(2):161-5.

74. Kamel SR, Omar GM, Darwish AF, Asklany HT, Ellabban AS. Asymptomatic pulmonary hypertension in systemic lupus erythematosus. Clin Med Insights Arthritis Musculoskelet Disord. 2011;4:77-86

75. Miller RF, Kaski JP, Hakim J, Matenga J, Nathoo K, Munyati S, Desai SR, Corbett EL, Ferrand RA. Cardiac disease in adolescents with delayed diagnosis of vertically acquired HIV infection. Clin Infect Dis. 2013;56(4):576-82.

76. Oguanobi NI, Ejim EC, Anisiuba BC, Onwubere BJ, Ike SO, Ibegbulam OG, Agwu O. Clinical and electrocardiographic evaluation of sickle-cell anaemia patients with pulmonary hypertension. ISRN Hematol. 2012;2012:768718.

77. Oguanobi NI, Ejim EC, Anisiuba BC, Onwubere BJC, Ike SO, Ibegbulam OG. Echocardiographic assessment of adult Nigerian sickle cell patients with pulmonary hypertension. Eur J Cardiovasc Med. 2015;3(1):430-4.

78. Orji FT, Adiele DK, Umedum NG, Akpeh JO, Ofoegbu VC, Nwosu JN: The clinical and radiological predictors of pulmonary hypertension in children with adenotonsillar hypertrophy. Eur Arch otorhinolaryngol 2016.

79. Zhang W, Mondo C, Okello E, Musoke C, Kakande B, Nyakoojo W, Kayima J, Freers J. Presenting features of newly diagnosed rheumatic heart disease patients in Mulago hospital: a pilot study. Cardiovasc J Afr. 2013;24(2):28-33.

80. Ezzahra SF, Meriam A, Rachida H. Echocardiographic assessment of pulmonary artery systolic pressure and outcomes in ambulatory heart failure patients: a moroccan study. Cardiovasc J Afr. 2015:26(5):29.

81. Farrag A, El-Aroussy W, Zaghloul S, El-Guindy M, Yacoub M. Prevalence and severity of pulmonary hypertension in asymptomatic rural residents with schistosomal infection in the Nile Delta. Trop Med Int Health. 2012;17(1):112-8.

82. Farrag AAM, El Aroussy W, Zaghloul S, El Guindy M, Yacoub M. Assessment of right ventricular function and severity of pulmonary hypertension in subjects previously infected with schistosomaisis in Nile Delta. Eur Heart J. 2011;32:598.

83. Rifaie $\mathrm{O}, \mathrm{El}$-Damanhory $\mathrm{H}, \mathrm{Amr} \mathrm{M}$, Nammas W. Prevalence and predictors of pulmonary hypertension in elderly patients with isolated diastolic heart failure. Kardiol Pol. 2010;68(6):655-61.

84. Silva PS, Cartacho MP, Castro CC, Salgado Filho MF, Brandao AC. Evaluation of the influence of pulmonary hypertension in ultra-fast-track anesthesia technique in adult patients undergoing cardiac surgery. Rev Bras Cir Cardiovasc. 2015;30(4):449-58.

85. Soliman EZ, Sharma S, Arasteh K, Wohl D, Achhra A, Tambussi G, O'Connor J, Stein JH, Duprez DA, Neaton JD, et al. Baseline cardiovascular risk in the 
INSIGHT strategic timing of AntiRetroviral treatment (START) trial. HIV Med. 2015;16(Suppl 1):46-54.

86. Simonneau G, Gatzoulis MA, Adatia I, Celermajer D, Denton C, Ghofrani A, Gomez Sanchez MA, Krishna Kumar R, Landzberg M, Machado RF, et al.

Updated clinical classification of pulmonary hypertension. J Am Coll Cardiol. 2013;62(25 Suppl):D34-41.

Submit your next manuscript to BioMed Central and we will help you at every step:

- We accept pre-submission inquiries

- Our selector tool helps you to find the most relevant journal

- We provide round the clock customer support

- Convenient online submission

- Thorough peer review

- Inclusion in PubMed and all major indexing services

- Maximum visibility for your research

Submit your manuscript at www.biomedcentral.com/submit 